Int. J. Electrochem. Sci., 15 (2020) 9849 - 9863

International Journal of

ELECTROCHEMICAL

SCIENCE

WWW.electrochemsci.org

\title{
Hierarchically Flower-Like Cobalt Oxide@Doped-Sn Carbon Nanofiber with Core-Shell structure as Anodes for Lithium Ion Battery
}

\author{
Hong Wang ${ }^{1}$, Jingyu Zhou ${ }^{2}$, Jun Sun ${ }^{2}$, Yan Wang ${ }^{2}$, Yuejin Ma ${ }^{1, *}$, Zelin Bai ${ }^{3, *}$, Yajun Zhao ${ }^{2, *}$, \\ Wenming Zhang, ${ }^{2, *}$ \\ ${ }^{1}$ College of Mechanical and Electrical Engineering, Hebei Agricultural University, Baoding 071001, \\ China. \\ ${ }^{2}$ National-Local Joint Engineering Laboratory of New Energy Photoelectric Devices, College of \\ Physics Science and Technology, Hebei University, Baoding, Hebei 071002, China. \\ ${ }^{3}$ Department of Geriatrics, The First Affiliated Hospital to Changchun University of Chinese \\ Medicine, Changchun, Jilin 130021, China. \\ "E-mail: myj@hebau.edu.cn (Y. M), ZelinBai_CCUCM@126.com (Z. Bai), yjzhaohbu@126.com (Y. \\ Zhao), wmzhanghbu@126.com (W. Zhang)
}

doi: $10.20964 / 2020.10 .14$

Received: 13 August 2019 / Accepted: 19 November 2019 / Published: 31 August 2020

Coaxial core-shell hierarchical flower-like cobalt oxide@doped-Sn carbon nanofiber $\left(\mathrm{Co}_{3} \mathrm{O}_{4} @ \mathrm{Sn}-\mathrm{CNF}\right)$ prepared by loading $\mathrm{Co}_{3} \mathrm{O}_{4}$ shells on $\mathrm{Sn}-\mathrm{CNF}$ that were synthesized via electrostatic spinning and subsequently thermally treated by electrophoretic deposition were used as the anode material for lithiumion batteries in this paper. The $\mathrm{Co}_{3} \mathrm{O}_{4}$ shells were not solid but flower-like, provided abundant inner space, facilitated the transfer of lithium ions and electrons and the contact with the electrolyte via the increase in space, increased the electrochemical reaction sites, and improved the electrochemical performance. After the initial discharge specific capacity of $1519 \mathrm{mAh} \mathrm{g}^{-1}$, the discharge specific capacity of the $\mathrm{Co}_{3} \mathrm{O}_{4} @$ Sn-CNF reached $1000 \mathrm{mAh} \mathrm{g}^{-1}$ without an obvious capacity decay, and the coulombic efficiency reached $98.6 \%$, indicating the excellent cycle stability of this material. In addition, a specific capacity recovery of $90 \%$ demonstrated a remarkable rate performance. The improvement in the electrochemical performance was due to the introduction of the Sn-CNF, which had a good electroconductivity and mitigated the volume deformation due to the elastic deformation of the CNF, in addition to the unique and firm structure.

Keywords: core-shell structure, cobalt oxide, doped-Sn, carbon nanofiber, lithium ion battery. 
(C) 2020 The Authors. Published by ESG (www.electrochemsci.org). This article is an open access article distributed under the terms and conditions of the Creative Commons Attribution license (http://creativecommons.org/licenses/by/4.0/). 